\title{
Autophagy in Pulmonary Diseases
}

\author{
Kiichi Nakahira, Maria Angelica Pabon Porras, and Augustine M. K. Choi \\ Division of Pulmonary and Critical Care Medicine, Joan and Sanford I. Weill Department of Medicine, Weill Cornell Medicine, New York, \\ New York
}

\begin{abstract}
The pathogenesis of pulmonary diseases is often complex and characterized by multiple cellular events, including inflammation, cell death, and cell proliferation. The mechanisms by which these events are regulated in pulmonary diseases remain poorly understood. Autophagy is an essential process for cellular homeostasis and stress adaptation in eukaryotic cells. This highly conserved cellular process involves the sequestration of cytoplasmic components in double-membrane autophagosomes, which are
\end{abstract}

delivered to lysosomes for degradation. The critical roles of autophagy have been demonstrated in a wide range of pathophysiological conditions. Emerging studies have identified that autophagy plays important roles in the pathogenesis of various lung diseases. In addition, autophagy has been shown to selectively degrade subcellular targets, including proteins, organelles, and pathogens. Here, we highlight the recent advances in the molecular regulation and function of autophagy in lung diseases.

Keywords: autophagy; pulmonary diseases; mitochondria

\section{Contents \\ Molecular Regulation of Autophagy \\ Measurement of Autophagy and Mitophagy \\ Function of Autophagy \\ Autophagy in Pulmonary Diseases COPD \\ Cystic Fibrosis \\ Mtb Infection \\ Sepsis \\ Idiopathic Pulmonary Fibrosis \\ Autophagy as a Potential Therapeutic Target \\ Conclusions}

Despite recent progress in patient care and interventions, many pulmonary diseases still lack effective treatments and remain incurable diseases. Chronic obstructive pulmonary disease (COPD) is the fourth leading cause of death in the United States (1), and lung cancer is by far the leading cause of cancer death among both men and women (2). Thus, there is a need to develop new therapeutic targets for such pulmonary diseases. Macroautophagy (hereafter referred to as autophagy) is a cellular selfdegradation process that facilitates the lysosomal breakdown of intracellular material and organelles sequestered within autophagosomes (3-5). This degradation and recycling process is essential for cellular homeostasis and stress adaptation and is well conserved among most of eukaryotic life. During autophagy, cytosolic "cargos" (e.g., proteins, lipids, and organelles) are delivered into double-membrane vesicles, termed autophagosomes, and subsequently fuse with lysosomes (Figure 1) (3-5). Autophagy cargos sequestered in lysosomes are digested by lysosomal hydrolases to their basic components (e.g., amino acids and fatty acids), which are recycled for macromolecular synthesis and energy production for cell survival. In addition, autophagy exerts cytoprotective functions by removing potentially "harmful" cytosolic substances, such as protein aggregates or damaged organelles (e.g., mitochondria) $(3,4,6)$. A failure to clear deleterious cytosolic substrates, such as damaged mitochondria, may cause cellular dysfunctions that lead to pathological conditions (3-5). Autophagy is highly inducible by environmental stressors, and it thereby constitutes an important part of the mammalian stress and adaptive responses.

Since the autophagosome structure was observed in mammalian cells in the 1950s (7), the formation of autophagy has been reported in various cell types and tissues (8). Initial studies describing the molecular mechanisms and functions of autophagy were mainly from genetic screens including identifying a series of autophagy-related genes (Atg) in yeast, such as Saccharomyces cerevisiae (7). To date, a number of studies suggest that autophagy is regulated in various pathophysiological conditions and functionally involved in the pathogenesis and development of diseases including

(Received in original form December 21, 2015; accepted in final form August 30, 2016)

Supported by National Institutes of Health grants P01 HL108801, R01 HL079904, and R01HL060234 (A.M.K.C.).

Correspondence and requests for reprints should be addressed to Augustine M. K. Choi, M.D., Joan and Sanford I. Weill Department of Medicine, Weill Cornell Medicine, 525 East 68th Street, Room M-522, Box 130, New York, NY 10065. E-mail: amchoi@med.cornell.edu

This article has an online supplement, which is accessible from this issue's table of contents at www.atsjournals.org

Am J Respir Crit Care Med Vol 194, Iss 10, pp 1196-1207, Nov 15, 2016

Copyright $\odot 2016$ by the American Thoracic Society

Originally Published in Press as DOI: 10.1164/rccm.201512-2468SO on August 31, 2016

Internet address: www.atsjournals.org 

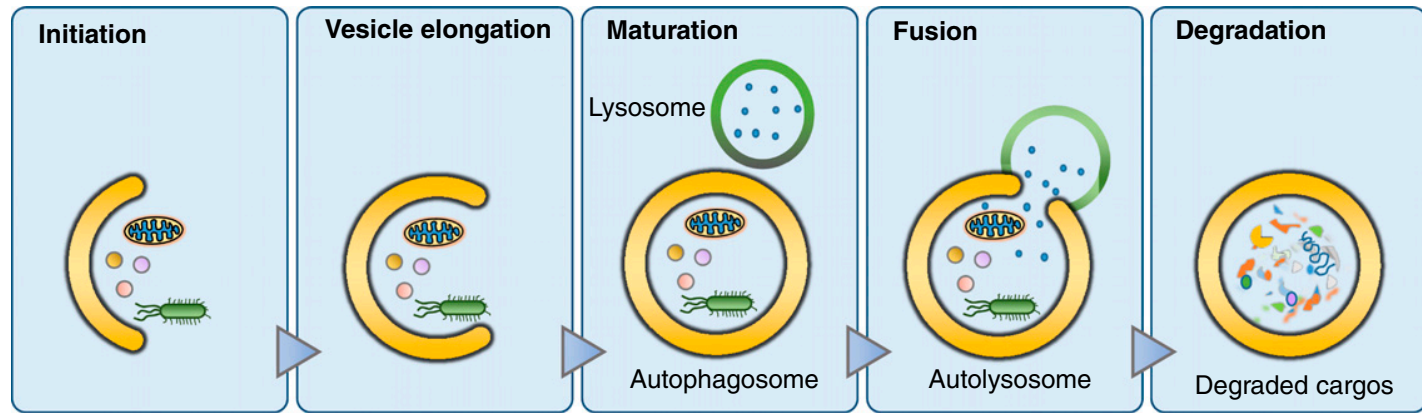

Figure 1. Schema of the autophagy pathway. The autophagy pathway proceeds through several phases, including initiation (formation of a preautophagosomal structure leading to an isolation membrane, or phagophore), vesicle elongation, autophagosome maturation and sequestration of cytosolic cargo, and autophagosome-lysosome fusion. In the final stage, lysosomal acid hydrolases degrade autophagosomal contents, which are released for metabolic recycling.

cancer, neurodegenerative disorders, and metabolic and infectious diseases $(3-5,9)$ In addition, recent studies suggest that autophagy can selectively degrade subcellular proteins, organelles, and bacteria in processes termed "selective autophagy" $(3,4,10)$. Since our review of autophagy in the Journal in 2011 (11), a number of advances have been made, especially in our improved understanding of the functional roles of autophagy in experimental and human lung diseases. In this review, we aim to summarize the current understanding of the regulation and function of autophagy, with an emphasis on the importance of selective autophagy in the pathogenesis of lung diseases and its therapeutic targets.

\section{Molecular Regulation of Autophagy}

Environmental cues activate autophagy through regulatory factors that initiate autophagy machinery, which consists of homologs of similar autophagy-related (Atg) proteins originally identified in yeast (7). The autophagy process can be divided into six steps (Figures 1 and 2): (1) activation of molecular signaling pathways (by nutrient signals), (2) isolation of membrane as an initiation step, (3) vesicle elongation, (4) cargo loading and maturation (autophagosome formation), (5) fusion with lysosome (autolysosome formation), and (6) degradation. Autophagy is negatively regulated by nutrient and growth factor-related signals through the activation of the mammalian target of rapamycin (mTOR) (Figure 2) $(3-5,7)$. In contrast, nutritional starvation activates autophagy through the inhibition of the mTOR pathway (Figure 2). The autophagy pathway is also promoted by the activation of the $5^{\prime}$-adenosine monophosphate (AMP)-activated protein kinase (AMPK) in response to energy depletion (Figure 2). Along with these molecular regulators and signals, Beclin 1 participates in autophagosomal nucleation and formation (Figure 2). The elongation and maturation of the autophagosome requires two ubiquitinlike conjugation systems: the ATG5-ATG12ATG16L1 and the microtubule-associated protein-1 light chain-3 (LC3) conjugation systems (Figure 2). In the final stage, autophagosomal contents are degraded by lysosomal acid hydrolases, and the contents of the autolysosome are released for metabolic recycling (Figure 1).

\section{Measurement of Autophagy and Mitophagy}

The growing interest in the field of autophagy has led to a number of technical and scientific advances in vitro and in vivo. We provide an updated summary of the measurement of autophagy and its activity in the online supplement (Table E1).

\section{Function of Autophagy}

Autophagy acts as a survival mechanism under conditions of various environmental stresses to maintain cellular integrity by regenerating metabolic precursors and clearing subcellular debris. Previously, autophagy was believed to be a process whereby subcellular compartments are recycled randomly through nonspecific encapsulation of cytosolic materials. However, recent studies have demonstrated that autophagy selectively recognizes and captures substrates, a process that is regulated by cargo-specific factors (selective autophagy) (Figure 3) $(3,5,10)$. Furthermore, this specialized autophagy has also been shown to regulate various pathophysiological conditions $(3,4)$. The modification of subcellular targets by ubiquitination is a critical step for identification of selective autophagy substrates $(3,5,10)$. Selective autophagy contributes to the turnover of cellular organelles (e.g., mitochondria through the process of "mitophagy") (Figure 4) and the clearance of polyubiquitinated protein aggregates (i.e., aggrephagy) $(3-5,10)$. Dysfunctional mitochondria or protein aggregates can be accumulated during stress, aging, and diseases, which may lead to further increase of oxidative stress, inflammation, and cell death. Therefore, defective selective autophagy may exacerbate pathological conditions or severity of diseases. Interestingly, autophagy is also implicated as a regulator of lipid metabolism (i.e., lipophagy) and bronchial cilia (i.e., ciliophagy) (4).

Although autophagy machinery acts as a cell survival mechanism to prevent cell death, interactions of autophagy- and apoptosis-related molecules such as Beclin 1 and BCL-2 (12), or LC3B and Fas (13), suggest complex cross-talk between cell survival and death. A recent study suggests implication of selective autophagy (mitophagy) on necroptosis, a programmed 


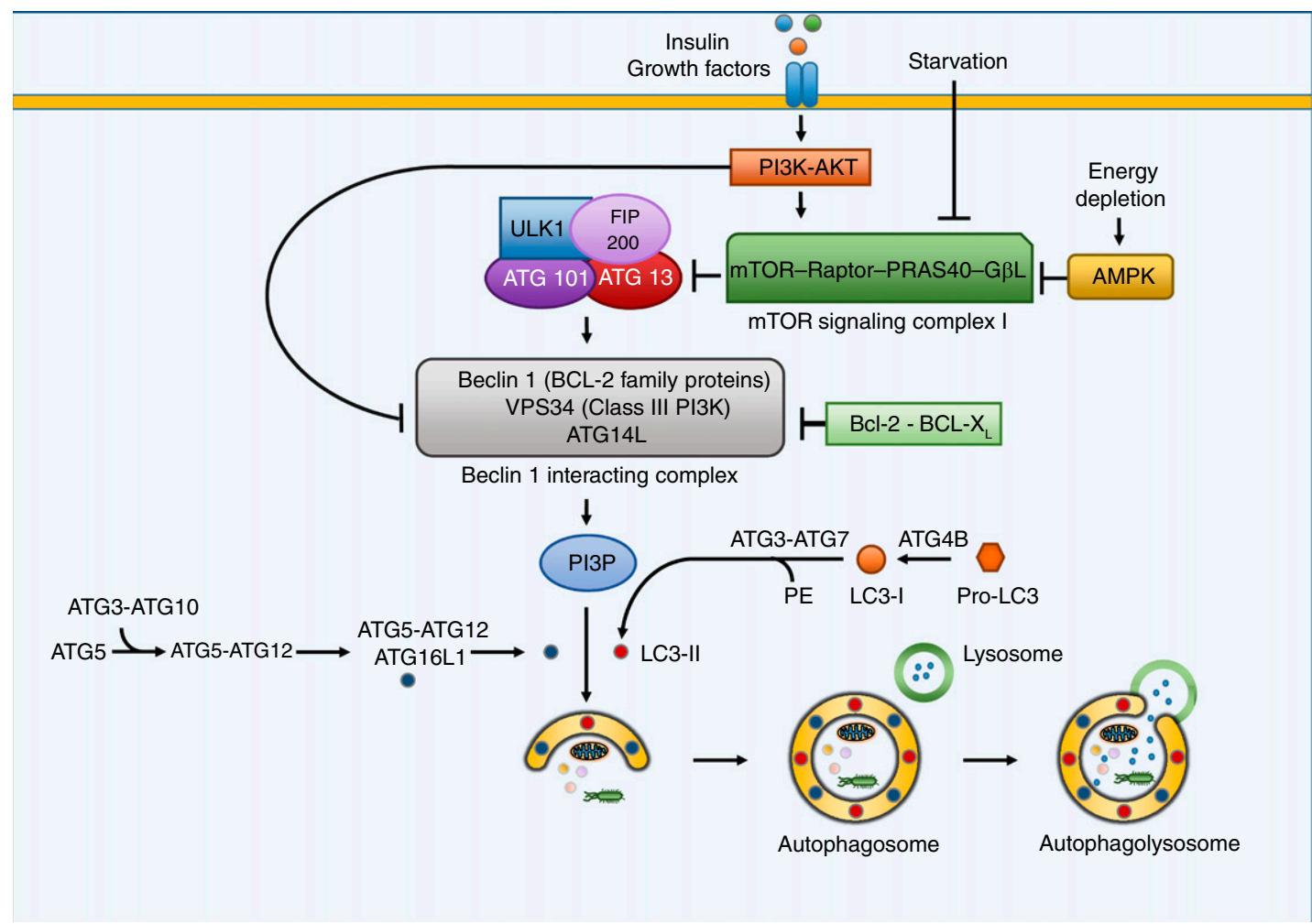

Figure 2. Molecular mechanism of autophagosome formation. Nutrient signals modulate mammalian target of rapamycin (mTOR) pathways. In response to insulin or other growth factors, class I phosphatidylinositol-3-kinase (PI3K)-AKT activates mTOR, which acts as a negative regulator of autophagy. AKT may also negatively regulate autophagy by phosphorylating Beclin 1. Cellular energy depletion (e.g., decrease of intracellular ATP/adenosine monophosphate [AMP] ratio) can activate AMP-activated protein kinase (AMPK). Activated AMPK negatively regulates mTOR and consequently activates UNC-51-like kinase 1 (ULK1), thereby acting as a positive regulator of autophagy in response to energy depletion. The mTOR protein resides in mTOR signaling complex 1 (mTORC1), consisting of the regulatory-associated protein of mTOR (Raptor), G protein $\beta$ subunit-like protein (GßL), and proline-rich Akt substrate of $40 \mathrm{kD}$ (PRAS40), which in turn negatively regulates the mTOR substrate complex consisting of ULK1, autophagy-related (ATG)13, ATG101, and FIP200. Under conditions of nutrient depletion, mTORC1 activity is inhibited and therefore promotes ULK1 activity, leading to autophagy activation. Autophagy is also activated by the Beclin 1-interacting complex, consisting of Beclin 1, class III phosphatidylinositol-3-kinase (PIK3C3, or VPS34), and ATG14L. This Beclin 1 complex generates phosphatidylinositol-3-phosphate (PI3P), which promotes autophagosomal membrane nucleation. B-cell lymphoma 2 (BCL-2) family proteins interact with Beclin 1 to inhibit autophagy. Autophagosomal elongation requires two ubiquitin-like conjugation systems. The ubiquitin-like protein ATG12 is conjugated to ATG5 by ATG7 and ATG10 enzymes. The ATG5-ATG12 complex further forms a complex with ATG16L1, which promotes elongation of the autophagy membrane. Another conjugation system requires microtubule-associated protein 1 light chain 3 (LC3). LC3 is modified with the cellular lipid phosphatidylethanolamine (PE). The precursor form of LC3 is cleaved by the protease ATG4B to generate the LC3-I. ATG7 and ATG3 participate in the conjugation of PE with LC3-I (free form) for conversion to LC3-II (PE-conjugated form). In mammals, this conversion of LC3-I to LC3-II is a key regulatory step in autophagosome formation. The conversion of LC3-I (unconjugated cytosolic form) to LC3-II (autophagosomal membrane-associated PE-conjugated form) is regarded as an indicator of autophagosome formation. FIP200 = FAK family kinase-interacting protein of $200 \mathrm{kD}$.

necrosis (14), which is regulated by several key molecules, including mixed lineage kinase domain-like protein (MLKL) and receptor interacting serine/threonineprotein kinase 3 (RIPK3), and implicated in various human diseases (15).

Autophagy also regulates various immune responses during infection. Autophagy contributes to the host defense mechanism by providing intracellular lysosomal degradation of invading pathogens, termed "xenophagy" (Figure 3) $(9,16,17)$. In addition to its direct role in pathogen clearance, autophagy also enhances host defense by increasing immune recognition of infected cells via the generation of antigenic bacterial peptides (18). Since Beclin 1 was shown to be protective against $\alpha$ virus encephalitis in 1998 (19), many studies have demonstrated the protective role of autophagy against invading pathogens $(16,17)$. Microbes that can be eliminated by autophagy include bacteria (e.g., group A Streptococcus, Mycobacterium tuberculosis (Mtb), Shigella flexneri, Salmonella enterica, Listeria monocytogenes, and Klebsiella pneumoniae), viruses (e.g., herpes simplex virus type 1 and chikungunya virus), and parasites such as
Toxoplasma gondii $(16,17)$. However, emerging studies suggest that the functions of autophagy on host defense differ among microbes. Some microbes, such as hepatitis $\mathrm{C}$ virus or HIV-1, can adapt to autophagy machinery and evade or use autophagy machinery to promote survival or replication $(16,17)$

To avoid excess inflammation during infection, selective autophagy also participates in the regulation of immune responses. Invasion of microbes can cause oxidative stress and dysregulated mitochondrial function. Mitophagy controls innate immune responses by preserving 


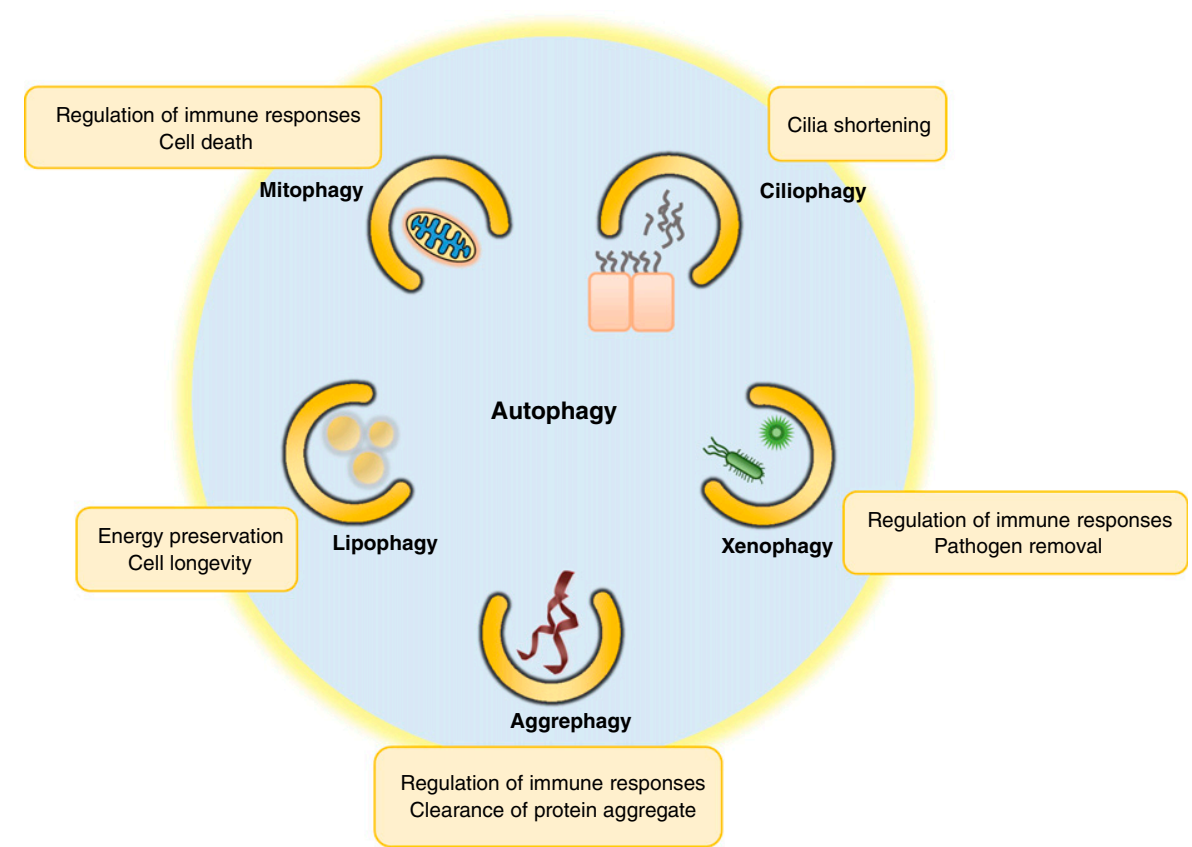

Figure 3. Subtypes of selective autophagy. Selective autophagy refers to the specific targeting of cellular subcomponents for autophagy degradation. The turnover of mitochondria through selective autophagy pathways is termed "mitophagy." The capacity of autophagy to clear intracellular pathogens, such as bacteria, viruses, and parasites, is collectively referred to as "xenophagy." "Aggrephagy" refers to the selective autophagy degradation of cytosolic protein aggregates. The specific degradation of airway epithelial cilia components is regulated by autophagy ("ciliophagy"). Autophagy also regulates intracellular lipid stores, cellular levels of free lipids such as fatty acids, and energy homeostasis ("lipophagy"). Defect of distinctive selective autophagy may cause accumulation of harmful cytosolic bulks (e.g., intracellular pathogens, dysfunctional mitochondria, and protein aggregates) or metabolic deregulation, resulting in excessive immune responses, cell death, or pathogen growth. In contrast, selective autophagy, such as mitophagy, may contribute to pro-cell survival in certain oxidative stress conditions (e.g., exposure to cigarette smoke).

mitochondrial integrity. Mitophagy deficiency may lead to the accumulation of dysfunctional mitochondria with increased mitochondrial reactive oxygen species (mtROS) generation and the leakage of (oxidized) mitochondrial DNA (mtDNA) into cytosol (Figure 5A) (20-22).

Consequently, this accumulation of damaged mitochondria due to defective mitophagy promotes immune responses, in particular the inflammasome $(4,21,22)$. Inflammasome is a multiprotein complex to promote caspase-1-mediated secretion of proinflammatory cytokines IL- $1 \beta$ and IL-18 and pyroptosis (macrophage cell death), which is implicated in a wide range of human diseases (23). Autophagy (mitophagy) machinery has been shown as a critical negative regulatory mechanisms of the inflammasome. The functions of autophagy on type I IFN signaling pathways in viral infection models are also well reported (Figure 5B and 5C). Autophagy activation negatively regulates innate antiviral immune responses by inhibiting interaction of retinoic acidinducible gene-I-like receptors and mitochondrial antiviral signaling protein (also known as IPS-1, VISA, and CARDIF) (Figure 5B) (24). ATG9 inhibits the activation of simulator of IFN gene (STING) by inhibiting assembly of STING and TANK-binding kinase I, resulting in the suppression of type I IFN production (Figure 5C) (25). Beclin 1 suppresses type I IFN response by directly binding to cyclic GMP-AMP synthase in response to viral DNA (26).

Autophagy is also critically involved in the adaptive immune system by affecting the functions of $\mathrm{T}$ cells, memory B cells, and plasma cells $(9,16,17)$. Autophagy regulates the balance between myeloid and lymphoid progenitors and their differentiation (9). Furthermore, autophagy is involved with major histocompatibility complex class II antigen presentation for both intracellular and extracellular antigens and enhances antimicrobial host defense $(9,17)$. For example, autophagy delivers cytosolic proteins to the lumen of antigenprocessing compartments and promotes major histocompatibility complex class II antigen presentation in extracellular space $(9,17)$. Autophagy can also contribute to the maintenance of memory B cells and regulate the secretion of immunoglobulins $(9,27,28)$.

Thus, autophagy is implicated a wide range of cellular functions and physiology. Pathological relevance of autophagy and genetic mutation of autophagy in human diseases is described in the online supplement.

\section{Autophagy in Pulmonary Diseases}

As diverse pathophysiological roles of autophagy have been revealed, a number of studies exploring the roles of autophagy in lung disease also have been reported. Figure 6 and Table E2 show recent studies showing the regulation and functions of autophagy in the field of lung. In this section, we discuss representative pulmonary diseases in which autophagy (particularly selective autophagy) is implicated in experimental pulmonary disease models and patients with pulmonary diseases.

\section{COPD}

Autophagy in COPD. In 2000, the potential implication of autophagy in pulmonary diseases was realized when autophagic vacuoles were observed in a liver biopsy specimen from a patient with alpha-1 antitrypsin deficiency, a mutation associated with the development of emphysema (29). Although emphysema can be developed even without a history of significant smoking in patients with alpha-1 antitrypsin deficiency, this observation enabled physicians and scientists to hypothesize that autophagy is involved in the pathogenesis of COPD. Chen and colleagues reported that the expression of LC3B-II, a marker of autophagosome formation, and key autophagy-associated proteins such as ATG4, ATG5-ATG12, and 


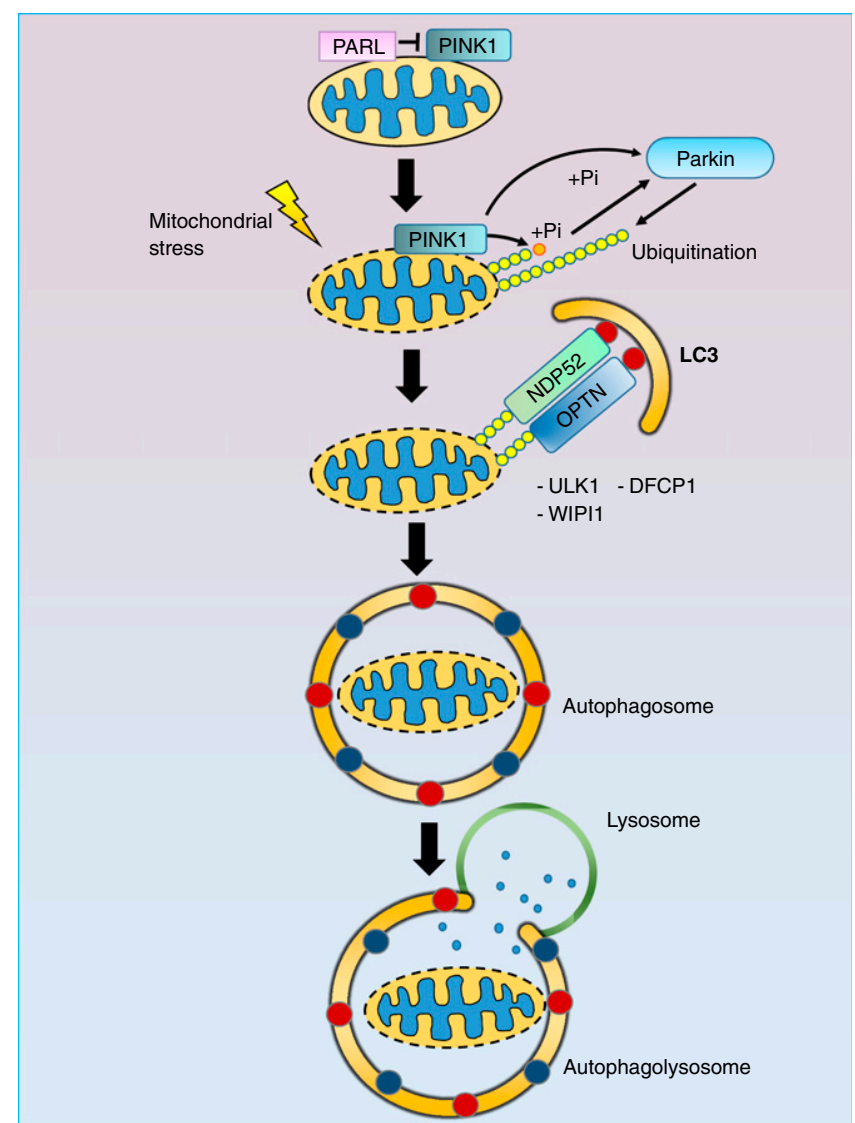

Figure 4. Molecular mechanism of mitophagy. In healthy mitochondria, PARL cleaves PTEN-induced putative kinase 1 (PINK1). On mitochondrial stress, activated PINK1 becomes stabilized on the outer mitochondrial membrane, phosphorylates serine 65 (Ser65) of ubiquitin, and activates cytosolic Parkin, which assembles polyubiquitin chains on the outer mitochondrial membrane. Subsequently, optineurin (OPTN) and nuclear dot protein 52 (NDP52) are recruited to phosphorylated ubiquitin on mitochondria $(17,18)$. PINK1 also recruits OPTN and NDP52, which recruit ULK1, DFCP1, WIPI1, and LC3 to generate autophagosome-initiating autophagy machinery. DFCP1 = double FYVEcontaining protein 1; LC3 = microtubule-associated protein light chain 3; PARL = presenilinsassociated rhomboid-like protein; PTEN = phosphatase and tensin homolog; ULK1 = UNC-51-like kinase 1; WIPI1 = WD-repeat domain phosphoinositide-interacting 1.

ATG7 was increased in COPD lung relative to control lung (30). Electron microscopic analysis revealed increased autophagosome formation in lung tissues from patients with COPD compared with control tissues (30).

In experimental models of COPD, autophagy proteins and autophagosome formation are also increased in the lungs of mice exposed to environmental cigarette smoke (CS), which induces air space enlargement in the lung. Importantly, LC3B-deficient mice are resistant to CS-induced air space enlargement (13), suggesting the implication of autophagy in the pathogenesis of emphysema (loss of alveolar surface area). Subchronic CS exposure for 3 weeks disrupts mucociliary clearance in the airways of mice, indicating the pathogenesis of bronchitis associated with COPD (31). Autophagy protein-depleted mice are also resistant to mucociliary clearance disruption in the airways after CS exposure (31). These studies indicate that the autophagy pathway contributes to the development of COPD.

\section{Implication of selective autophagy in} COPD. The mechanisms underlying the pathogenesis of COPD remain incompletely understood but implicate aberrant cellular responses in bronchial cells, alveolar epithelial cell, and immune cells (e.g., alveolar macrophages) in response to CS (32-34). Although promoting epithelial cell death by autophagy in the context of CS was shown as a potential mechanism $(13,30)$, it has remained unclear how and which selective autophagy contributes to the development of COPD. The implication of mitochondria in COPD has been reported $(35,36)$; therefore, it is plausible that selective autophagy machinery can target dysfunctional mitochondria in COPD. Indeed, the subsequent study demonstrated that a key mitophagy protein, phosphatase and tensin homolog (PTEN)-induced putative kinase 1 (PINK1), is increased in the lungs of patients with COPD (14). Genetic deficiency of PINK1 and pharmacological inhibition of mitophagy by Mdivi-1 ameliorates mitochondrial dysfunction, air space enlargement, and mucociliary clearance disruption in mice during CS exposure (14). Mechanistically, mitophagy contributes to the development of COPD by promoting necroptosis, a programmed form of necrotic cell death (14). Although the precise mechanism by which mitophagy regulates necroptosis in response to CS remains unclear, these results suggest the important roles of mitophagy in determining cell death modes.

Selective autophagy also contributes to mucociliary clearance disruption during CS exposure. CS exposure promotes shortening of respiratory epithelial cell cilia and increases histone deacetylase 6 (HDAC6) in tracheal epithelial cells.

HDAC6, a critical regulator of primary cilia resorption, also regulates autophagy at the step of autophagosome-lysosome fusion (31). CS-induced cilia shortening is suppressed in autophagy protein-depleted mice and HDAC6-deficient mice (31). Thus, autophagy also targets bronchial cilia for degradation (i.e., ciliophagy) mediated by HDAC6 in COPD models (37)

In contrast to these selective autophagy modes (mitophagy and ciliophagy), alveolar macrophages from smokers display loss of autophagy activity and defective delivery of bacteria to lysosomes (38). The digestion of intracellular microbes through autophagy machinery (xenophagy) is an important host defense system in alveolar air space. The impairment of this selective autophagy in alveolar macrophages by CS may be a possible cause of the recurrent airway infections in patients with COPD. Thus, multiple selective autophagy pathways are involved in COPD models.

These studies now raise questions regarding the regulation and function of 


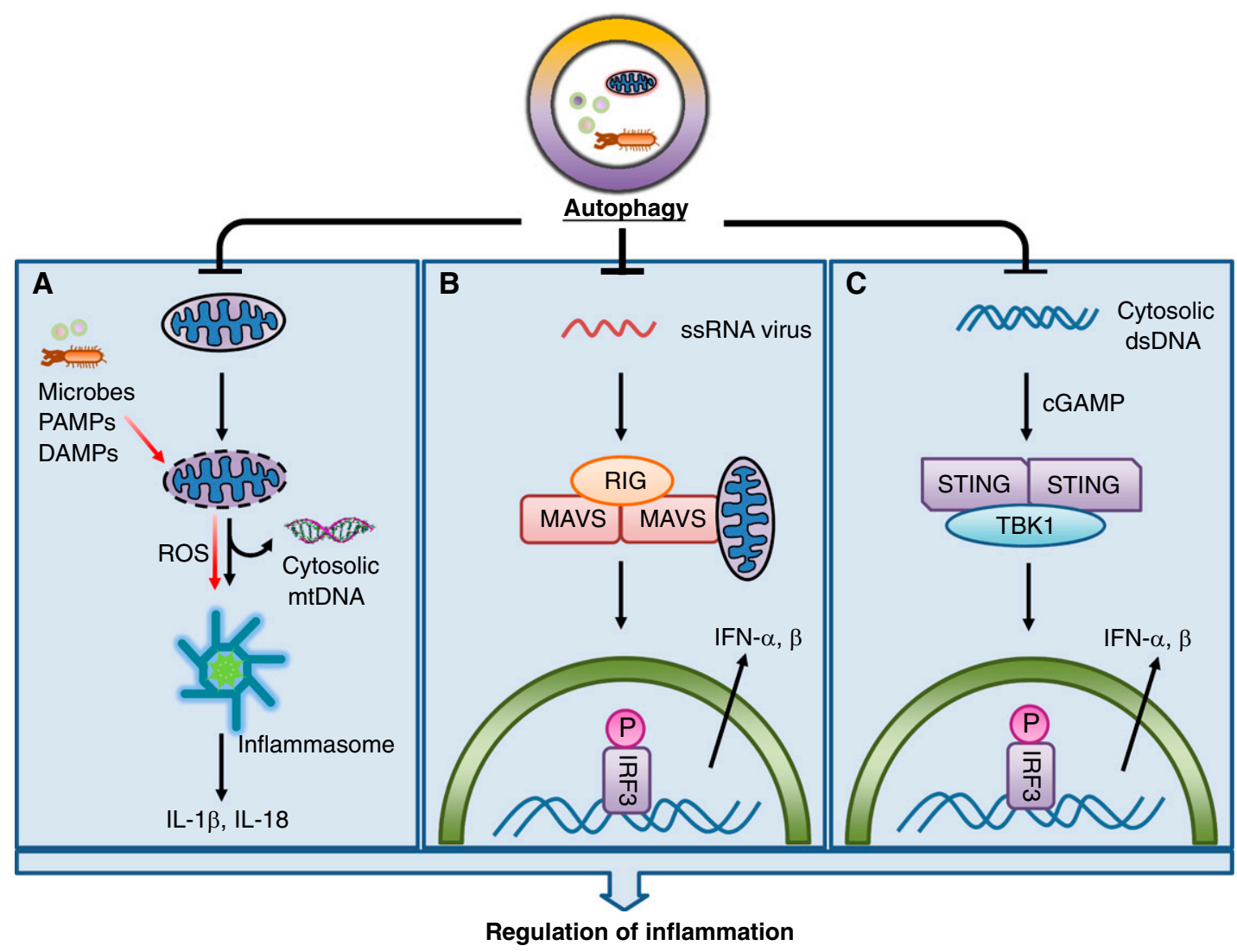

Figure 5. Immunological functions of autophagy. (A) Autophagy can negatively regulate inflammasome-mediated maturation and secretion of proinflammatory cytokines (e.g., IL-1 $\beta$ and IL-18) in response to pathogens or pathogen-associated molecules. During inflammatory stimuli, mitochondria are damaged and increase mitochondrial reactive oxygen species (mtROS) generation and translocation of mitochondrial DNA (mtDNA) to cytosol, which promotes NLRP3-mediated inflammasome activation. Absence of autophagy increases accumulation of dysfunctional mitochondria and enhances inflammasome activation. (B) ssRNA viruses are recognized by the members of the retinoic acid-inducible gene I (RIG-I)-like receptors (RLRs) in the cytosol. ATG5-ATG12 conjugates block RLR signaling by direct C-terminal caspase-recruitment domain-mediated association with RIG-I and MAVS, which reside in mitochondria. ATG5 deficiency enhances RLR signaling and increased IFN secretion, accompanied by increased mtROS generation. (C) Autophagy contributes to the down-regulation of IFN-mediated immune response. Cytosolic dsDNA, such as cytosolic mtDNA or viral DNA, activates cyclic GMP-AMP (cGAMP) synthase to form 2' $3^{\prime}$-cGAMP, which activates stimulator of IFN genes (STING) through a series of structural changes. Activated STING then recruits TBK1 to phosphorylate IFN regulatory factor 3 (IRF3), resulting in the production of type I IFNs and other cytokines. ATG9 can suppress activation of STING, therefore regulating IRF3-mediated proinflammatory cytokine production. ATG = autophagy protein; DAMP= damage-associated molecular pattern; dsDNA = double-stranded DNA; MAVS = mitochondrial antiviral-signaling protein; NLRP3 = NLR family, pyrin domaincontaining 3; PAMP = pathogen-associated molecular pattern; ssRNA = single-stranded RNA; TBK1 = TANK-binding kinase-1.

autophagy in COPD. First, given that a number of studies showed protective effects of autophagy in various stress models, why does autophagy (particularly mitophagy and ciliophagy) display deleterious effects in COPD models? One hypothesis is that continual activation of autophagy by chronic CS exposure may exceed the beneficial aspect of autophagy-mediated cell death (e.g., actively removing dysfunctional epithelial cells), which may lead to disruption of alveolar structure. Second, how can CS differentially regulate selective autophagy between epithelial cells and macrophages? It remains unclear how autophagy machineries are differentially regulated among cell types; however, this unique regulation of autophagy may be partly due to cell-specific metabolic regulation (39). Finally, it is also important to investigate cross-talk of autophagy among different organs or tissues. COPD is known to be associated with various complications, such as anemia, osteoporosis, and muscle dysfunction. For example, in the vastus lateralis, LC3B protein lipidation is increased in patients with COPD and inversely correlates with thigh cross-sectional area, $\mathrm{FEV}_{1}$, and $\mathrm{FEV}_{1} / \mathrm{FVC}$ ratio (40). Although further studies will be needed to elucidate the precise roles of autophagy in COPD, these studies suggest that autophagy is not just a cellular recycling system, but it exerts regulations and functions among different types of cells in COPD.

\section{Cystic Fibrosis}

Selective autophagy in cystic fibrosis. Cystic fibrosis (CF) is a fatal autosomal recessive disease, which is caused by mutation in the gene encoding the cystic fibrosis transmembrane conductance regulator (CFTR) (41-43). CF is characterized by abnormally viscous mucous, which obstructs organ passages, resulting in recurrent pulmonary infections. The most common CFTR mutation is a deletion of phenylalanine at position $508\left(\mathrm{CFTR}^{\mathrm{F} 508 \mathrm{del}}\right)$ 


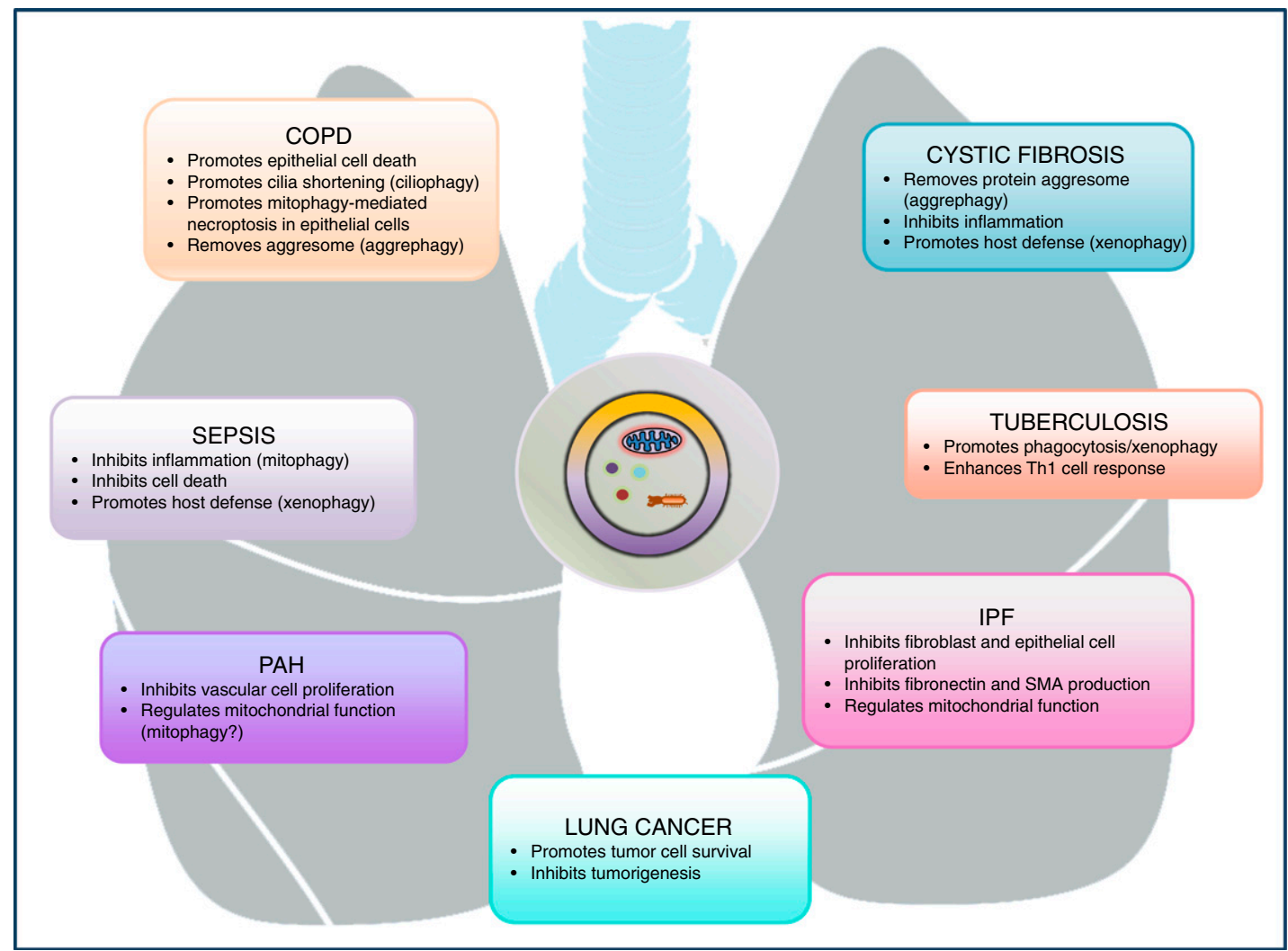

Figure 6. Roles of autophagy in pulmonary diseases. Autophagy may prevent or promote the development or progression of pulmonary diseases by exerting its diverse functions. These functions include the regulation of cell death (or survival), innate and adaptive immune responses, and cell proliferation. Specialized functions of autophagy (selective autophagy, such as mitophagy or xenophagy) may more directly contribute to the regulation of pathogenesis in pulmonary diseases. COPD = chronic obstructive pulmonary disease; IPF = idiopathic pulmonary fibrosis; PAH= pulmonary arterial hypertension; SMA = smooth muscle actin; Th1 = T helper type 1 .

in the CFTR gene $(41,43)$. Knockdown of CFTR or overexpression of CFTR ${ }^{\text {F508del }}$ results in increased ROS production and tissue transglutaminase, which leads to inactivation of key autophagy molecule Beclin 1 (44). Cells with CFTR ${ }^{\text {F508del }}$ display accumulated polyubiquitinated proteins, decreased clearance of aggresome, and defective autophagy $(44,45)$. Importantly, restoration of autophagy by overexpression of Beclin 1 ameliorates inflammatory responses (44), suggesting a critical role of removal of protein aggregate by autophagy machinery (i.e., aggrephagy). Similarly, mice bearing the F508del-CFTR mutation whose phenotypes include body weight loss and short lifespan also display low levels of Beclin 1 expression (46). In addition to the significance of aggrephagy, impairment of xenophagy in CF may be responsible for the recurrence of infection. Mice harboring the F508 mutation display exacerbated acute lung injury in response to infection with Burkholderia cenocepacia (47). However, restoration of autophagy by rapamycin reduces the bacterial number and suppresses lung inflammation and injury (47).

Significance of selective autophagy in patients with $C F$. Selective autophagy may also affect intervention for patients with CF. Long-term use of azithromycin has been shown to improve clinical outcomes in patients with pulmonary diseases such as $\mathrm{CF}$ and COPD $(48,49)$, possibly due to its antiinflammatory properties (50). However, several studies report a synchronous increase of mycobacterial infection in patients with $\mathrm{CF}$, predominantly with the highly pathogenic nontuberculous mycobacteria Mycobacterium abscessus $(51,52)$. This paradoxical consequence of azithromycin treatment in patients with $\mathrm{CF}$ may be due to the inhibitory effect of azithromycin on lysosomal acidification, thereby impairing autophagic and phagosomal degradation. As a result, azithromycin may inhibit intracellular killing of mycobacteria within macrophages of the patients (i.e., impairment of xenophagy) (53). Therefore, the increased infection rates with nontuberculous mycobacteria seen in patients with CF using azithromycin may be due to decreased xenophagy induced by the drug in addition to dysregulated autophagy in patients with CF. These studies highlight the significance of selective autophagy activity in CF.

Therapies that restore autophagy function may offer an additional therapeutic potential in the treatment of CF.

Interestingly, oral treatment of cysteamine, a reduced form of cystamine and an approved drug for the treatment of cystinosis (54), restores Beclin 1 expression and improves the lifespan of F508del-CFTR mutant mice (54). In fact, cysteamine is known to induce autophagy, and therefore it may be valuable to study cytoprotective mechanisms of cysteamine as a potential therapeutic agent for CF through restoration of autophagy $(54,55)$. 


\section{Mtb Infection}

Autophagy promotes Mtb killing. The beneficial roles of autophagy in the control of Mtb have been extensively studied by multiple laboratory groups $(9,56-59)$. Mtb interferes with phagosome maturation by the inhibition of phagosome-lysosome fusion, which results in diminished acidification of the phagosomal compartments, allowing persistence of $\mathrm{Mtb}$ in the phagosome. Induction of autophagy by rapamycin or starvation promotes conversion of Mtb phagosomes into autolysosomes, which contain a greater number of antimicrobial compartments (e.g., antimicrobial peptide) than conventional phagolysosomes $(9,56,60,61)$. Autophagy also enhances presentation of mycobacterial antigen in macrophages (58). A recent study identified a key mechanism whereby autophagy targets Mtb in phagocytes such as macrophages (i.e., molecular mechanisms of xenophagy). Extraembryonic spermatogenic homeobox 1 (ESX-1) secretion system (62), a virulence factor of $\mathrm{Mtb}$, promotes the exposure of $\mathrm{Mtb}$ DNA to host cytosol by permeabilizing the phagosome membrane (63). The exposed bacterial DNA is recognized by a cytosolic DNA sensor molecule, such as STING, and ubiquitinated (63). The ubiquitinated bacterial DNA binds to LC3 via adaptor protein p62 or nuclear dot protein 52 and is subsequently capsulated in the autophagosome for fusion with lysosome (63)

Autophagy in tuberculosis. Although molecular mechanisms of selective autophagy in Mtb-infected cells have been extensively studied, researchers also expanded studies to explore potential therapeutic approaches for tuberculosis. For example, vitamin D stimulates autophagy activation against $\mathrm{Mtb}$ through induction of cathelicidins (64). Interestingly, decreased levels of serum vitamin $\mathrm{D}$ are associated with higher risk of active tuberculosis (65). Although recent clinical studies suggest that vitamin $\mathrm{D}$ supplementation does not significantly affect time to sputum culture conversion $(66,67)$, it is also reported that vitamin $D$ reduces time to sputum culture conversion in patients with vitamin D receptor polymorphism (67). The cocktail of isoniazid and pyrazinamide is the first-line standard drug for the treatment of tuberculosis. Intriguingly, isoniazid and pyrazinamide promote autophagy activation and phagosomal maturation in Mtb-infected host cells, which may be part of a potential mechanisms of these antimycobacterial drugs (59).

Although a number of studies support the significance of autophagy in tuberculosis, a recent study suggests dispensable roles of autophagy in tuberculosis. Myeloid cell-specific ATG5 deficiency increases Mtb replication and reduces the survival in mice infected with Mtb; however, such phenotypes are not observed when other autophagy genes, such as ATG3, ATG7, ATG12, and ATG16, are knocked down (68). In addition, ATG5 plays a unique role in protection against Mtb by preventing polymorphonuclear cell-mediated immunopathology (68). These observations suggest that ATG5 may function in nonautophagic processes that contribute to Mtb control in mice. Autophagy in nonimmune cells may be more critically involved in host defense of tuberculosis than that in myeloid cells. Further studies will be necessary to investigate these differential effects of autophagy proteins in tuberculosis models.

\section{Sepsis}

Autophagy in sepsis. Although immune responses are essential for host defense against sepsis, excess immune responses and inflammation often trigger tissue/organ injury and subsequent secondary infection $(69,70)$. The implication of autophagy in sepsis has been suggested by transmission electron microscopy studies on liver samples obtained from patients with sepsis (71). The transmission electron microscopy studies demonstrate the increased number of autophagy vacuoles in the liver of the patients with sepsis compared with patients without sepsis (71). Autophagy activity is assessed by flux of autophagic substrates to the lysosome and degradation of autophagic substrates inside the lysosome (online supplement) (72). Therefore, it is unclear whether this increase of autophagy vacuoles observed in the patients represents increased autophagy activity in patients with sepsis or inhibition of autophagy that led to the inappropriate accumulation of autophagosomes. However, these observations suggest the implication of autophagy in human sepsis.

The significant roles of autophagy have been demonstrated in preclinical models of sepsis, such as cecal ligation and puncture (CLP)-induced polymicrobial sepsis and an endotoxin-induced septic shock. Autophagy-associated proteins (e.g., LC3B) are up-regulated in major target organs of sepsis, including lung, liver, and kidneys of mice subjected to CLP or endotoxin administration $(73,74)$. Beneficial roles of autophagy in sepsis models are reported by using various genetically engineered mice or pharmacological autophagy modulators. Genetic depletion of autophagy genes such as MAP1LC3B, BECN1, and Vps34 increases inflammation, bacterial burden, organ injury, and mortality in septic mice induced by CLP or LPS $(21,74)$. In contrast, pharmacological activators of autophagy such as rapamycin or genetic overexpression of LC3 suppresses inflammatory response and apoptotic activity and improves the survival in mice subjected to CLP (75-77). Genetics studies suggest the significance of autophagy in sepsis. For example, polymorphism of immunity-related GTPase $\mathrm{M}$, an important molecule to regulate autophagy induction and eliminate intracellular mycobacteria (78), is associated with the mortality of patients with severe sepsis (79). Carriage of the minor A allele of ATG16 is also associated with sepsis severity and ventilator-associated pneumonia (80).

Role of selective autophagy in sepsis. Although regulating inflammation is an important arm to prevent multiorgan dysfunctions in sepsis, proper immune responses are critical to the elimination of microbes during infection. In this respect, autophagy can up-regulate both immune functions (i.e., increasing bacterial killing and suppressing inflammation) mediated by xenophagy and mitophagy. Virulent pathogens killing by xenophagy may contribute to decreasing the number of the pathogens, resulting in immune responses and inflammation during sepsis. In addition to xenophagy, autophagy may also regulate immune responses and inflammation by controlling mitochondrial quality in sepsis. The levels of mtDNA are increased in plasma from patients with sepsis and associated with severity and mortality $(81,82)$. In contrast, a recent study shows that copy number of mtDNA in monocytes and lymphocytes of patients with sepsis has been shown to decrease and inversely correlate with severity of 
illness (e.g., Acute Physiology and Chronic Health Evaluation II score, a commonly used scoring system for a mortality estimation) (83), suggesting that mtDNA can be released from these cells. The release of mtDNA from mitochondria is associated with mtROS-mediated NLRP3 (NLR family, pyrin domain-containing 3) inflammasome activation (21). Thus, these results suggest that mitochondrial integrity may be impaired in human sepsis.

Dysfunctional mitochondria can enhance mitochondrial ROS generation and NLRP3 inflammasome activation, leading to cell death and secretion of proinflammatory cytokines. Autophagy (especially mitophagy) removes those dysfunctional mitochondria to maintain cellular homeostasis. Dysfunctional mitochondria caused by infection or oxidative stress during sepsis can be one of the main causes for immune responses; therefore, eliminating those mitochondria by mitophagy machinery is critical for regulating immune responses and inflammation. In fact, LC3B puncta is increased and colocalized with mitochondria in the distal lung of septic mice induced by Staphylococcus aureus infection (84). Functionally, depletion of LC3B and Beclin 1 further increases production of IL-1 $\beta$ and IL-18 and mortality in septic mice (21). Furthermore, deficiency of Parkin exhibits impaired recovery of cardiac contractility in LPS-treated septic mice (85). The kinase Jnk2 (JNK2)-deficient mice displaying defective mitophagy also cause hyperactivation of inflammasomes and increase mortality in endotoxic shock (22).

Recent studies suggest deregulation of cellular metabolic pathways, including glycolysis, de novo lipid synthesis, and free fatty acid synthesis, is crucial for inflammasome activation, where mitochondria-associated molecules such as hexokinase 1 (HK-1), uncoupling protein-2 (UCP2), and NADPH oxidase 4 (NOX4) are crucially involved (86-88). The immunomodulatory effect of mitophagy may be associated with cellular metabolic changes. Although significant roles of autophagy in immune cells such as macrophages are well documented, it remains unclear whether other types of cells can contribute to the pathogenesis of sepsis. Given the complex nature of pathology in sepsis, further studies using cell-specific target knockout of autophagy genes using lox-system knockout mice or bone marrow transplantation studies (to generate chimera mice) (68) would be important to determine the roles of autophagy on various cell types/tissues in sepsis.

\section{Idiopathic Pulmonary Fibrosis}

\section{Autophagy in idiopathic pulmonary}

fibrosis. Idiopathic pulmonary fibrosis (IPF) is a progressive fibroproliferative lung disease of unknown cause $(89,90)$. Unlike COPD, LC3-II expression is decreased in lung tissues from patients with IPF compared with lung from normal subjects $(30,91,92)$. In contrast, phosphorylation of $\mathrm{S} 6$, an indicator of mTOR activation, is increased in fibroblast foci of IPF lung tissue, suggesting down-regulation of autophagy in IPF (93). In experimental models of IPF, up-regulation of autophagy by rapamycin inhibits transforming growth factor- $\beta$-induced fibronectin and $\alpha$-smooth muscle actin expression in lung fibroblasts (91) and collagen production in lung epithelial cells (94). Similarly, rapamycin also inhibits anti-Toll-like receptor 4 antibody- or bleomycin-induced lung fibrosis in mice $(91,94,95)$. In contrast, deficiency of autophagy genes such as MAP1LC3B, ATG5, and BECN1 or pharmacological inhibition of autophagy promotes transforming growth factor$\beta$-induced activation of lung fibroblasts $(91,94)$. Consistently, autophagy inhibition by alveolar epithelial cell-specific knockdown of TSC1 exacerbates bleomycin-mediated lung injury in mice (93). Thus, autophagy is likely to exert beneficial roles on IPF models.

Selective autophagy in IPF. A recent study has revealed the accumulation of dysmorphic and dysfunctional mitochondria in lung epithelial cells, especially alveolar type II cells (AECIIs), from the lungs of patients with IPF (96). High mitochondrial content was observed, especially in AECIIs lining the areas of honeycombs and dense fibrosis, whereas no differences in mitochondrial content were observed in airway epithelial cells between IPF and donor control lungs (96).

Microarray analyses showed the decrease of PINK1 expression in lung samples from patients with IPF (96), and this downregulation of PINK1 was observed in AECIIs of patients with IPF but not in the fibroblasts (96). These observations suggest deregulated mitochondria homeostasis and also implication of selective autophagy targeting mitochondria in IPF.

Functionally, genetic knockdown of
PINK1 displays increased mitochondria depolarization and expression of profibrotic factors in mice $(96,97)$. The mechanism of antifibrotic effect by PINK1 may include prevention of cell death by preserving mitochondrial function of pulmonary epithelial cells $(96,97)$. In addition, Parkinson protein 2 E3 ubiquitin protein ligase (PARK2), another key mitophagyassociated molecule, is also implicated in myofibroblast differentiation and proliferation (98), although function of PARK2 on lung fibrosis needs to be further investigated $(98,99)$. It remains unclear whether the observed accumulation of dysfunctional mitochondria and defective mitophagy in the lung of patients with IPF is a consequence of IPF or cause of IPF. Unlike CS-associated COPD, various factors are associated with onset of IPF. Further studies are necessary to investigate the upstream mechanism by which mitophagy is regulated in IPF.

\section{Autophagy as a Potential Therapeutic Target}

Drugs modulating autophagy, such as rapamycin or chloroquine, have been clinically used for many years $(100,101)$. These autophagy modulators are also now tested in clinical trials targeting pulmonary diseases, including lung cancer (102). The details of ongoing clinical trials targeting modulating autophagy are listed at https://www.clinicaltrials.gov/ct2/results? term=autophagy. Currently, more than 30 different classes of drugs to modulate autophagy activity have been synthesized and identified (102-104). Of note, newclass autophagy modulators such as temsirolimus/CCI-779 or everolimus (mTORC1 inhibitors) display improved specificity and effectiveness and have been recently approved for the treatment of cancer (105). Recent studies suggest use of selective autophagy modulators such as Mdivi-1 can regulate pathological conditions in experimental pulmonary diseases $(14,106)$. The development of modulators targeting each selective autophagy pathway may be also beneficial, as those modulators can avoid unnecessary manipulation of other autophagy pathways, therefore having fewer off-target effects.

However, there are several important points to be further investigated. For example, effective and less-invasive methods 
to monitor autophagy activity for patients (e.g., biomarkers) are not currently available. In addition, because of its fundamental cellular process and functions, it is plausible that modulating autophagy causes other untoward effects that may be clinically deleterious. Although autophagy has been shown to be beneficial for infectious diseases, up-regulation of autophagy may be harmful in certain disease conditions, such as COPD or cancer. It is also important to consider that each cell type may have distinct autophagy regulation and display unexpected cellular responses to autophagy modulators. Autophagy is upregulated in lung epithelial cells in response to CS $(13,30)$, whereas autophagy activity is suppressed in CS-exposed alveolar macrophages (38). If patients with COPD are to receive intervention targeting down-regulation of autophagy, there is a possibility that the interventions may cause defective bacterial killing in alveolar macrophages and lead to respiratory infections and acute exacerbation of COPD.
Considering the beneficial aspects of autophagy, such as in host defense and even antiaging effects (online supplement), the modulation of autophagy (including selective autophagy) may serve as a potential intervention for various human diseases. Further understanding of cell-specific and/or selective autophagy regulation and better technologies of autophagy manipulation with minimal off-target effect may promote the development of optimized autophagy modulators.

\section{Conclusions}

The pathophysiologic role of autophagy has been extensively studied as a potential new therapeutic target. As described in this review, autophagy is involved in the pathogenesis of various preclinical models of pulmonary diseases and is likely to be regulated in human pulmonary diseases. Although autophagy has been initially believed to serve to act as a cytoprotective process in most host responses, recent studies suggest the diverse functions of autophagy in lung diseases, including potentially deleterious effects in specific pathophysiological states, such as COPD, cancer, and avian influenza virus-mediated pneumonia (Figure 6 and Table E2). In addition, the recent recognition of molecular regulation and function of specialized autophagy is of significance. During the last 5 years, the implication of selective autophagy in pulmonary diseases has been extensively reported. Of note, multiple selective autophagy pathways can uniquely regulate pathogenesis of each disease. Implication of selective autophagy in human diseases may be more complex but also substantially important. Studies of the regulation and roles of each selective autophagy may reveal new pathological mechanisms of human diseases, which may lead to potential therapeutic targets.

Author disclosures are available with the text of this article at www.atsjournals.org.

\section{References}

1. Berry CE, Wise RA. Mortality in COPD: causes, risk factors, and prevention. COPD 2010;7:375-382.

2. American Cancer Society. Key statistics for lung cancer. 2016 [last medical review 2016 Feb 8; accessed 2016 Mar]. Available from: www.cancer.org/cancer/lungcancer-non-smallcell/detailedguide/nonsmall-cell-lung-cancer-key-statistics

3. Mizushima N, Komatsu M. Autophagy: renovation of cells and tissues. Cell 2011;147:728-741.

4. Choi AM, Ryter SW, Levine B. Autophagy in human health and disease. N Engl J Med 2013;368:1845-1846.

5. Ravikumar B, Sarkar S, Davies JE, Futter M, Garcia-Arencibia M, GreenThompson ZW, Jimenez-Sanchez M, Korolchuk VI, Lichtenberg M, Luo $\mathrm{S}$, et al. Regulation of mammalian autophagy in physiology and pathophysiology. Physiol Rev 2010;90:1383-1435.

6. Youle RJ, Narendra DP. Mechanisms of mitophagy. Nat Rev Mol Cell Biol 2011;12:9-14.

7. He C, Klionsky DJ. Regulation mechanisms and signaling pathways of autophagy. Annu Rev Genet 2009;43:67-93.

8. Collet AJ, Chevalier G. Morphological aspects of type II alveolar pneumocytes following treatment with puromycin in vivo. Am J Anat 1977;148:275-293.

9. Deretic V, Kimura T, Timmins G, Moseley P, Chauhan S, Mandell M. Immunologic manifestations of autophagy. J Clin Invest 2015;125:75-84.

10. Stolz A, Ernst A, Dikic I. Cargo recognition and trafficking in selective autophagy. Nat Cell Biol 2014;16:495-501.

11. Haspel JA, Choi AM. Autophagy: a core cellular process with emerging links to pulmonary disease. Am J Respir Crit Care Med 2011;184:1237-1246.

12. Pattingre S, Tassa A, Qu X, Garuti R, Liang XH, Mizushima N, Packer M, Schneider MD, Levine B. Bcl-2 antiapoptotic proteins inhibit Beclin 1-dependent autophagy. Cell 2005;122:927-939.

13. Chen ZH, Lam HC, Jin Y, Kim HP, Cao J, Lee SJ, Ifedigbo E, Parameswaran H, Ryter SW, Choi AM. Autophagy protein microtubule-associated protein 1 light chain-3B (LC3B) activates extrinsic apoptosis during cigarette smoke-induced emphysema. Proc Natl Acad Sci USA 2010;107:18880-18885.
14. Mizumura K, Cloonan SM, Nakahira K, Bhashyam AR, Cervo M, Kitada T, Glass K, Owen CA, Mahmood A, Washko GR, et al. Mitophagydependent necroptosis contributes to the pathogenesis of COPD. J Clin Invest 2014;124:3987-4003.

15. Linkermann A, Green DR. Necroptosis. N Engl J Med 2014;370:455-465.

16. Deretic V, Levine B. Autophagy, immunity, and microbial adaptations. Cell Host Microbe 2009;5:527-549.

17. Levine B, Mizushima N, Virgin HW. Autophagy in immunity and inflammation. Nature 2011;469:323-335.

18. Paludan C, Schmid D, Landthaler M, Vockerodt M, Kube D, Tuschl T, Münz C. Endogenous MHC class II processing of a viral nuclear antigen after autophagy. Science 2005;307:593-596.

19. Liang XH, Kleeman LK, Jiang HH, Gordon G, Goldman JE, Berry G, Herman B, Levine B. Protection against fatal Sindbis virus encephalitis by beclin, a novel Bcl-2-interacting protein. J Virol 1998;72:8586-8596.

20. Tal MC, Sasai M, Lee HK, Yordy B, Shadel GS, Iwasaki A. Absence of autophagy results in reactive oxygen species-dependent amplification of RLR signaling. Proc Natl Acad Sci USA 2009;106:2770-2775.

21. Nakahira K, Haspel JA, Rathinam VA, Lee SJ, Dolinay T, Lam HC, Englert JA, Rabinovitch M, Cernadas M, Kim HP, et al. Autophagy proteins regulate innate immune responses by inhibiting the release of mitochondrial DNA mediated by the NALP3 inflammasome. Nat Immunol 2011;12:222-230.

22. Zhang Q, Kuang H, Chen C, Yan J, Do-Umehara HC, Liu XY, Dada L, Ridge KM, Chandel NS, Liu J. The kinase Jnk2 promotes stress-induced mitophagy by targeting the small mitochondrial form of the tumor suppressor ARF for degradation. Nat Immunol 2015;16:458-466.

23. Guo H, Callaway JB, Ting JP. Inflammasomes: mechanism of action, role in disease, and therapeutics. Nat Med 2015;21:677-687.

24. Jounai N, Takeshita F, Kobiyama K, Sawano A, Miyawaki A, Xin KQ, Ishii KJ, Kawai T, Akira S, Suzuki K, et al. The Atg5 Atg12 conjugate associates with innate antiviral immune responses. Proc Natl Acad Sci USA 2007;104:14050-14055.

25. Saitoh T, Fujita N, Hayashi T, Takahara K, Satoh T, Lee H, Matsunaga K, Kageyama S, Omori H, Noda T, et al. Atg9a controls dsDNA-driven dynamic translocation of STING and the innate immune response. Proc Natl Acad Sci USA 2009;106:20842-20846. 
26. Liang Q, Seo GJ, Choi YJ, Kwak MJ, Ge J, Rodgers MA, Shi M, Leslie BJ, Hopfner KP, Ha T, et al. Crosstalk between the cGAS DNA sensor and Beclin-1 autophagy protein shapes innate antimicrobial immune responses. Cell Host Microbe 2014;15:228-238.

27. Pengo N, Scolari M, Oliva L, Milan E, Mainoldi F, Raimondi A, Fagioli C, Merlini A, Mariani E, Pasqualetto E, et al. Plasma cells require autophagy for sustainable immunoglobulin production. Nat Immunol 2013;14:298-305.

28. Chen M, Hong MJ, Sun H, Wang L, Shi X, Gilbert BE, Corry DB, Kheradmand $F$, Wang J. Essential role for autophagy in the maintenance of immunological memory against influenza infection. Nat Med 2014;20:503-510.

29. Teckman JH, Perlmutter $\mathrm{DH}$. Retention of mutant alpha(1)-antitrypsin Z in endoplasmic reticulum is associated with an autophagic response. Am J Physiol Gastrointest Liver Physiol 2000;279:G961-G974.

30. Chen ZH, Kim HP, Sciurba FC, Lee SJ, Feghali-Bostwick C, Stolz DB, Dhir R, Landreneau RJ, Schuchert MJ, Yousem SA, et al. Egr-1 regulates autophagy in cigarette smoke-induced chronic obstructive pulmonary disease. Plos One 2008;3:e3316.

31. Lam HC, Cloonan SM, Bhashyam AR, Haspel JA, Singh A, Sathirapongsasuti JF, Cervo M, Yao H, Chung AL, Mizumura K, et al. Histone deacetylase 6-mediated selective autophagy regulates COPDassociated cilia dysfunction. J Clin Invest 2013;123:5212-5230.

32. Barnes PJ, Shapiro SD, Pauwels RA. Chronic obstructive pulmonary disease: molecular and cellular mechanisms. Eur Respir J 2003;22: 672-688.

33. Hogg JC, Timens W. The pathology of chronic obstructive pulmonary disease. Annu Rev Pathol 2009;4:435-459.

34. Barnes PJ. Immunology of asthma and chronic obstructive pulmonary disease. Nat Rev Immunol 2008;8:183-192.

35. Wiegman CH, Michaeloudes C, Haji G, Narang P, Clarke CJ, Russell KE, Bao W, Pavlidis S, Barnes PJ, Kanerva J, et al.; COPDMAP. Oxidative stress-induced mitochondrial dysfunction drives inflammation and airway smooth muscle remodeling in patients with chronic obstructive pulmonary disease. J Allergy Clin Immunol 2015; 136:769-780.

36. Sureshbabu A, Bhandari V. Targeting mitochondrial dysfunction in lung diseases: emphasis on mitophagy. Front Physiol 2013;4:384.

37. Cloonan SM, Lam HC, Ryter SW, Choi AM. "Ciliophagy": the consumption of cilia components by autophagy. Autophagy 2014;10:532-534.

38. Monick MM, Powers LS, Walters K, Lovan N, Zhang M, Gerke A Hansdottir S, Hunninghake GW. Identification of an autophagy defect in smokers' alveolar macrophages. J Immunol 2010;185: 5425-5435.

39. Yamada E, Bastie CC, Koga H, Wang Y, Cuervo AM, Pessin JE. Mouse skeletal muscle fiber-type-specific macroautophagy and muscle wasting are regulated by a Fyn/STAT3/Nps34 signaling pathway. Cell Reports 2012;1:557-569.

40. Guo Y, Gosker HR, Schols AM, Kapchinsky S, Bourbeau J, Sandri M, Jagoe RT, Debigaré R, Maltais F, Taivassalo T, et al. Autophagy in locomotor muscles of patients with chronic obstructive pulmonary disease. Am J Respir Crit Care Med 2013;188:1313-1320.

41. Stoltz DA, Meyerholz DK, Welsh MJ. Origins of cystic fibrosis lung disease. N Engl J Med 2015;372:351-362.

42. Rommens JM, lannuzzi MC, Kerem B, Drumm ML, Melmer G, Dean M, Rozmahel R, Cole JL, Kennedy D, Hidaka N, et al. Identification of the cystic fibrosis gene: chromosome walking and jumping. Science 1989;245:1059-1065.

43. Cutting GR. Cystic fibrosis genetics: from molecular understanding to clinical application. Nat Rev Genet 2015;16:45-56.

44. Luciani A, Villella VR, Esposito S, Brunetti-Pierri N, Medina D, Settembre C, Gavina M, Pulze L, Giardino I, Pettoello-Mantovani M, et al. Defective CFTR induces aggresome formation and lung inflammation in cystic fibrosis through ROS-mediated autophagy inhibition. Nat Cell Biol 2010;12:863-875.

45. Bence NF, Sampat RM, Kopito RR. Impairment of the ubiquitinproteasome system by protein aggregation. Science $2001 ; 292$ 1552-1555.

46. De Stefano D, Villella VR, Esposito S, Tosco A, Sepe A, De Gregorio F, Salvadori L, Grassia R, Leone CA, De Rosa G, et al. Restoration of CFTR function in patients with cystic fibrosis carrying the F508del-CFTR mutation. Autophagy 2014;10:2053-2074.
47. Abdulrahman BA, Khweek AA, Akhter A, Caution K, Kotrange S, Abdelaziz DH, Newland C, Rosales-Reyes R, Kopp B, McCoy K, et al. Autophagy stimulation by rapamycin suppresses lung inflammation and infection by Burkholderia cenocepacia in a model of cystic fibrosis. Autophagy 2011;7:1359-1370.

48. Martinez FJ, Curtis JL, Albert R. Role of macrolide therapy in chronic obstructive pulmonary disease. Int $J$ Chron Obstruct Pulmon Dis 2008;3:331-350.

49. McArdle JR, Talwalkar JS. Macrolides in cystic fibrosis. Clin Chest Med 2007;28:347-360.

50. Idris SF, Chilvers ER, Haworth C, McKeon D, Condliffe AM. Azithromycin therapy for neutrophilic airways disease: myth or magic? Thorax 2009;64:186-189.

51. Esther CR Jr, Esserman DA, Gilligan P, Kerr A, Noone PG. Chronic Mycobacterium abscessus infection and lung function decline in cystic fibrosis. J Cyst Fibros 2010;9:117-123.

52. Roux AL, Catherinot E, Ripoll F, Soismier N, Macheras E, Ravilly S, Bellis G, Vibet MA, Le Roux E, Lemonnier L, et al.; Jean-Louis Herrmann for the OMA Group. Multicenter study of prevalence of nontuberculous mycobacteria in patients with cystic fibrosis in France. J Clin Microbiol 2009;47:4124-4128.

53. Renna M, Schaffner C, Brown K, Shang S, Tamayo MH, Hegyi K, Grimsey NJ, Cusens D, Coulter S, Cooper J, et al. Azithromycin blocks autophagy and may predispose cystic fibrosis patients to mycobacterial infection. J Clin Invest 2011;121:3554-3563.

54. Gahl WA. Early oral cysteamine therapy for nephropathic cystinosis. Eur J Pediatr 2003;162:S38-S41.

55. Tosco A, De Gregorio F, Esposito S, De Stefano D, Sana I, Ferrari E, Sepe A, Salvadori L, Buonpensiero P, Di Pasqua A, et al. A novel treatment of cystic fibrosis acting on-target: cysteamine plus epigallocatechin gallate for the autophagy-dependent rescue of class II-mutated CFTR. Cell Death Differ 2016;23:1380-1393.

56. Gutierrez MG, Master SS, Singh SB, Taylor GA, Colombo MI, Deretic V. Autophagy is a defense mechanism inhibiting BCG and Mycobacterium tuberculosis survival in infected macrophages. Cell 2004;119:753-766.

57. Harris J, De Haro SA, Master SS, Keane J, Roberts EA, Delgado M, Deretic V. T helper 2 cytokines inhibit autophagic control of intracellular Mycobacterium tuberculosis. Immunity 2007;27:505-517.

58. Jagannath C, Lindsey DR, Dhandayuthapani S, Xu Y, Hunter RL Jr, Eissa NT. Autophagy enhances the efficacy of BCG vaccine by increasing peptide presentation in mouse dendritic cells. Nat Med 2009;15:267-276.

59. Kim JJ, Lee HM, Shin DM, Kim W, Yuk JM, Jin HS, Lee SH, Cha GH, Kim JM, Lee ZW, et al. Host cell autophagy activated by antibiotics is required for their effective antimycobacterial drug action. Cell Host Microbe 2012;11:457-468.

60. Ponpuak M, Davis AS, Roberts EA, Delgado MA, Dinkins C, Zhao Z, Virgin HW IV, Kyei GB, Johansen T, Vergne I, et al. Delivery of cytosolic components by autophagic adaptor protein p62 endows autophagosomes with unique antimicrobial properties. Immunity 2010;32:329-341.

61. Fabri M, Stenger S, Shin DM, Yuk JM, Liu PT, Realegeno S, Lee HM, Krutzik SR, Schenk M, Sieling PA, et al. Vitamin D is required for IFNgamma-mediated antimicrobial activity of human macrophages. Sci Transl Med 2011;3:104ra102.

62. Pym AS, Brodin P, Majlessi L, Brosch R, Demangel C, Williams A, Griffiths KE, Marchal G, Leclerc C, Cole ST. Recombinant BCG exporting ESAT-6 confers enhanced protection against tuberculosis. Nat Med 2003;9:533-539.

63. Watson RO, Manzanillo PS, Cox JS. Extracellular M. tuberculosis DNA targets bacteria for autophagy by activating the host DNA-sensing pathway. Cell 2012;150:803-815.

64. Yuk JM, Shin DM, Lee HM, Yang CS, Jin HS, Kim KK, Lee ZW, Lee SH, Kim JM, Jo EK. Vitamin D3 induces autophagy in human monocytes/ macrophages via cathelicidin. Cell Host Microbe 2009;6:231-243.

65. Nnoaham KE, Clarke A. Low serum vitamin D levels and tuberculosis: a systematic review and meta-analysis. Int J Epidemiol 2008;37:113-119.

66. Daley P, Jagannathan V, John KR, Sarojini J, Latha A, Vieth R, Suzana S, Jeyaseelan L, Christopher DJ, Smieja M, et al. Adjunctive vitamin D for treatment of active tuberculosis in India: a randomised, double-blind, placebo-controlled trial. Lancet Infect Dis 2015;15:528-534. 
67. Martineau AR, Timms PM, Bothamley GH, Hanifa Y, Islam K, Claxton AP, Packe GE, Moore-Gillon JC, Darmalingam M, Davidson RN, et al. High-dose vitamin $\mathrm{D}(3)$ during intensive-phase antimicrobial treatment of pulmonary tuberculosis: a double-blind randomised controlled trial. Lancet 2011;377:242-250.

68. Kimmey JM, Huynh JP, Weiss LA, Park S, Kambal A, Debnath J, Virgin HW, Stallings CL. Unique role for ATG5 in neutrophil-mediated immunopathology during $M$. tuberculosis infection. Nature 2015; 528:565-569.

69. Angus DC, van der Poll T. Severe sepsis and septic shock. N Engl J Med 2013;369:840-851.

70. Stearns-Kurosawa DJ, Osuchowski MF, Valentine C, Kurosawa S, Remick DG. The pathogenesis of sepsis. Annu Rev Pathol 2011;6:19-48.

71. Watanabe E, Muenzer JT, Hawkins WG, Davis CG, Dixon DJ, McDunn JE, Brackett DJ, Lerner MR, Swanson PE, Hotchkiss RS. Sepsis induces extensive autophagic vacuolization in hepatocytes: a clinical and laboratory-based study. Lab Invest 2009;89:549-561.

72. Mizushima N, Yoshimori T, Levine B. Methods in mammalian autophagy research. Cell 2010;140:313-326.

73. Lee S, Lee SJ, Coronata AA, Fredenburgh LE, Chung SW, Perrella MA, Nakahira K, Ryter SW, Choi AM. Carbon monoxide confers protection in sepsis by enhancing beclin 1-dependent autophagy and phagocytosis. Antioxid Redox Signal 2014;20:432-442.

74. Carchman EH, Rao J, Loughran PA, Rosengart MR, Zuckerbraun BS. Heme oxygenase-1-mediated autophagy protects against hepatocyte cell death and hepatic injury from infection/sepsis in mice. Hepatology 2011;53:2053-2062.

75. Lo S, Yuan SS, Hsu C, Cheng YJ, Chang YF, Hsueh HW, Lee PH, Hsieh YC. Lc3 over-expression improves survival and attenuates lung injury through increasing autophagosomal clearance in septic mice. Ann Surg 2013;257: 352-363.

76. Yen YT, Yang HR, Lo HC, Hsieh YC, Tsai SC, Hong CW, Hsieh CH. Enhancing autophagy with activated protein $\mathrm{C}$ and rapamycin protects against sepsis-induced acute lung injury. Surgery 2013;153:689-698.

77. Lin CW, Lo S, Perng DS, Wu DB, Lee PH, Chang YF, Kuo PL, Yu ML, Yuan SS, Hsieh YC. Complete activation of autophagic process attenuates liver injury and improves survival in septic mice. Shock 2014;41:241-249.

78. Singh SB, Davis AS, Taylor GA, Deretic V. Human IRGM induces autophagy to eliminate intracellular mycobacteria. Science 2006; 313:1438-1441.

79. Kimura T, Watanabe E, Sakamoto T, Takasu O, Ikeda T, Ikeda K, Kotani J, Kitamura N, Sadahiro T, Tateishi Y, et al. Autophagy-related IRGM polymorphism is associated with mortality of patients with severe sepsis. Plos One 2014;9:e91522.

80. Savva A, Plantinga TS, Kotanidou A, Farcas M, Baziaka F, Raftogiannis M, Orfanos SE, Dimopoulos G, Netea MG, Giamarellos-Bourboulis EJ. Association of autophagy-related 16-like 1 (atg16l1) gene polymorphism with sepsis severity in patients with sepsis and ventilator-associated pneumonia. Eur J Clin Microbiol Infect Dis 2014; 33:1609-1614.

81. Nakahira K, Kyung SY, Rogers AJ, Gazourian L, Youn S, Massaro AF, Quintana C, Osorio JC, Wang Z, Zhao Y, et al. Circulating mitochondrial DNA in patients in the ICU as a marker of mortality: derivation and validation. Plos Med 2013;10:e1001577; discussion e1001577.

82. Krychtiuk KA, Ruhittel S, Hohensinner PJ, Koller L, Kaun C, Lenz M, Bauer B, Wutzlhofer L, Draxler DF, Maurer G, et al. Mitochondrial DNA and toll-like receptor-9 are associated with mortality in critically ill patients. Crit Care Med 2015;43:2633-2641.

83. Pyle A, Burn DJ, Gordon C, Swan C, Chinnery PF, Baudouin SV. Fall in circulating mononuclear cell mitochondrial DNA content in human sepsis. Intensive Care Med 2010;36:956-962.

84. Chang AL, Ulich A, Suliman HB, Piantadosi CA. Redox regulation of mitophagy in the lung during murine Staphylococcus aureus sepsis. Free Radic Biol Med 2015;78:179-189.

85. Piquereau J, Godin R, Deschênes S, Bessi VL, Mofarrahi M, Hussain SN, Burelle Y. Protective role of PARK2/Parkin in sepsis-induced cardiac contractile and mitochondrial dysfunction. Autophagy 2013;9:1837-1851.

86. Moon JS, Lee S, Park MA, Siempos II, Haslip M, Lee PJ, Yun M, Kim CK, Howrylak J, Ryter SW, et al. UCP2-induced fatty acid synthase promotes NLRP3 inflammasome activation during sepsis. J Clin Invest 2015;125:665-680.
87. Moon JS, Hisata S, Park MA, DeNicola GM, Ryter SW, Nakahira K, Choi AM. mTORC1-induced HK1-dependent glycolysis regulates NLRP3 inflammasome activation. Cell Reports 2015;12: 102-115.

88. Moon JS, Nakahira K, Chung KP, DeNicola GM, Koo MJ, Pabón MA, Rooney KT, Yoon JH, Ryter SW, Stout-Delgado H, et al. NOX4dependent fatty acid oxidation promotes NLRP3 inflammasome activation in macrophages. Nat Med 2016;22:1002-1012.

89. Gross TJ, Hunninghake GW. Idiopathic pulmonary fibrosis. $N$ Engl $J$ Med 2001;345:517-525.

90. Wolters PJ, Collard HR, Jones KD. Pathogenesis of idiopathic pulmonary fibrosis. Annu Rev Pathol 2014;9:157-179.

91. Patel AS, Lin L, Geyer A, Haspel JA, An CH, Cao J, Rosas IO, Morse D. Autophagy in idiopathic pulmonary fibrosis. Plos One 2012;7: e41394.

92. Nho RS, Hergert P. IPF fibroblasts are desensitized to type I collagen matrix-induced cell death by suppressing low autophagy via aberrant Akt/mTOR kinases. Plos One 2014;9:e94616.

93. Gui YS, Wang L, Tian X, Li X, Ma A, Zhou W, Zeng N, Zhang J, Cai B, Zhang $\mathrm{H}$, et al. mTOR overactivation and compromised autophagy in the pathogenesis of pulmonary fibrosis. Plos One 2015;10: e0138625.

94. Mi S, Li Z, Yang HZ, Liu H, Wang JP, Ma YG, Wang XX, Liu HZ, Sun W, Hu ZW. Blocking IL-17A promotes the resolution of pulmonary inflammation and fibrosis via TGF-beta1-dependent and -independent mechanisms. J Immunol 2011;187:3003-3014.

95. Yang HZ, Wang JP, Mi S, Liu HZ, Cui B, Yan HM, Yan J, Li Z, Liu H, Hua F, et al. TLR4 activity is required in the resolution of pulmonary inflammation and fibrosis after acute and chronic lung injury. Am J Pathol 2012;180:275-292.

96. Bueno M, Lai YC, Romero Y, Brands J, St Croix CM, Kamga C, Corey C, Herazo-Maya JD, Sembrat J, Lee JS, et al. PINK1 deficiency impairs mitochondrial homeostasis and promotes lung fibrosis. J Clin Invest 2015;125:521-538.

97. Patel AS, Song JW, Chu SG, Mizumura K, Osorio JC, Shi Y, El-Chemaly S, Lee CG, Rosas IO, Elias JA, et al. Epithelial cell mitochondrial dysfunction and PINK1 are induced by transforming growth factorbeta1 in pulmonary fibrosis. Plos One 2015;10:e0121246.

98. Kobayashi K, Araya J, Minagawa S, Hara H, Saito N, Kadota T, Sato N, Yoshida M, Tsubouchi K, Kurita Y, et al. Involvement of park2mediated mitophagy in idiopathic pulmonary fibrosis pathogenesis. $J$ Immunol 2016;197:504-516.

99. Larson-Casey JL, Deshane JS, Ryan AJ, Thannickal VJ, Carter AB. Macrophage Akt1 kinase-mediated mitophagy modulates apoptosis resistance and pulmonary fibrosis. Immunity 2016;44: 582-596.

100. McCormack FX, Inoue Y, Moss J, Singer LG, Strange C, Nakata K, Barker AF, Chapman JT, Brantly ML, Stocks JM, et al.; National Institutes of Health Rare Lung Diseases Consortium; MILES Trial Group. Efficacy and safety of sirolimus in lymphangioleiomyomatosis. N Engl J Med 2011;364:1595-1606.

101. Kimura T, Takabatake Y, Takahashi A, Isaka Y. Chloroquine in cancer therapy: a double-edged sword of autophagy. Cancer Res 2013;73: 3-7.

102. Nakahira K, Choi AM. Autophagy: a potential therapeutic target in lung diseases. Am J Physiol Lung Cell Mol Physiol 2013;305: L93-L107.

103. Vakifahmetoglu-Norberg $\mathrm{H}$, Xia HG, Yuan J. Pharmacologic agents targeting autophagy. J Clin Invest 2015;125:5-13.

104. Rubinsztein DC, Codogno $\mathrm{P}$, Levine $\mathrm{B}$. Autophagy modulation as a potential therapeutic target for diverse diseases. Nat Rev Drug Discov 2012;11:709-730.

105. Wander SA, Hennessy BT, Slingerland JM. Next-generation mTOR inhibitors in clinical oncology: how pathway complexity informs therapeutic strategy. J Clin Invest 2011;121:1231-1241.

106. Marsboom G, Toth PT, Ryan JJ, Hong Z, Wu X, Fang YH, Thenappan T, Piao L, Zhang HJ, Pogoriler J, et al. Dynaminrelated protein 1-mediated mitochondrial mitotic fission permits hyperproliferation of vascular smooth muscle cells and offers a novel therapeutic target in pulmonary hypertension. Circ Res 2012;110:1484-1497. 